\title{
Objective and perceived oral health status of elderly nursing home residents: a local survey in southern France
}

This article was published in the following Dove Press journal:

Clinical Interventions in Aging

\author{
Gérald Maille ${ }^{1,2}$ \\ Bérengère Saliba-Serre ${ }^{1}$ \\ Anne-Marie Ferrandez' \\ Michel Ruquet ${ }^{1,2}$ \\ 'UMR 7268, Aix Marseille Univ, CNRS, \\ EFS, ADÉS, Marseille, France; ${ }^{2}$ Faculté \\ d'Odontologie, Assistance Publique \\ Hôpitaux de Marseille, Aix Marseille \\ Univ, Marseille, France
}

Objective: The aim of this study was to compare the perceived oral health of elderly persons and the clinical reality of their oral status.

Background: Persons aged over 60 have considerable need for oral health care; a need that increases over time. However, this population appears to be unaware of their state of oral health, and this may be a further obstacle to professional management. We thought it useful to examine the objective and the perceived oral health of these patients. Understanding what may influence their perception can help us to improve their management.

Methods: The data analyzed in this work are the findings of a field survey carried out in elderly nursing home residents. Their objective oral health was evaluated by using two variables: oral profile, determined by clinical examination, and the oral health index determined using the Oral Health Assessment Tool (OHAT). Perceived oral health was evaluated using the various categories and fields of the General Oral Health Assessment Index (GOHAI).

Results: Our clinical study showed a discrepancy between perceived oral health and the clinical reality: although a significant association can be demonstrated between the OHAT and the GOHAI, there are considerable variations. It also appeared that the number of teeth and total edentation considerably influence perceived oral health and that findings vary according to different situations.

Conclusion: Numerous factors influence elderly persons' perception of their true oral health. In order to improve our elders' quality of life, the necessary measures must be taken for the follow-up and regular monitoring of their oral health. At the same time, all possible means should be used and awareness should be raised to improve the health behavior and perception of patients and their entourage.

Keywords: aging, oral health, quality of life, dental health perception, dental care need

\section{Background}

Medical progress has largely contributed to increasing life expectancy, and there are over 604 million persons aged over 60 in the world. ${ }^{1}$ In France, the aging of the population is increasing under the double effect of greater life expectancy and the advance of the baby-boom generations. According to the estimations of the French National Institute of Statistics and Economic Studies (Institut National de la Statistique et des Etudes Economiques), the over-60s should represent over $32 \%$ of the French population in 2060 , or $8 \%$ more than on January $1,2014 .{ }^{2,3}$
Correspondence: Gérald Maille Faculté d'Odontologie, Aix-Marseille Université, 27 Boulevard Jean Moulin, I 3385 Marseille Cedex 5, France Email gerald.maille@univ-amu.fr 
Aging of the population inevitably leads to a greater number of dependent elderly persons and it is estimated that $1,200,000$ persons will be dependent in France in 2040 , compared with 800,000 in $2000 .^{4}$

All the health professions are thus increasingly faced with the management of elderly persons who are losing their independence. Beyond the specific disorders of the elderly patient, the level of dependence necessarily affects their management. This is also true of gerodontology: with regard to oral health, there is a high prevalence of dental disorders ${ }^{5-7}$ (caries, periodontal diseases, toothlessness) whose treatment is influenced by the patient's ability to cooperate, while loss of cognitive, motor and sensory faculties prevents maintenance of good oral hygiene. ${ }^{8,9}$ These disorders can have a considerable effect on health by increasing the risk of onset or aggravation of infections (respiratory in particular), cardiac disturbances and malnutrition, as microorganisms of oral origin are aggravating factors and cofactors of morbidity in the elderly. ${ }^{10-12}$

The immediate environment of these patients and their residential arrangements appear to play a capital role in improving the follow-up of their oral health. Important questions are raised in all developed countries as to the quality of care provided by residential institutions for the elderly, notably in comparison with management at home: ${ }^{13,14}$ the mere fact of living in an institution decreases visits to a dental surgeon by $25 \%$ compared with a population of independent elderly home-dwellers. ${ }^{15}$

Lastly, it should be stressed that poor oral health also affects the quality of life as it leads to deterioration of selfimage and of relationships with others. ${ }^{16,17}$

In a recent study that we carried out based on a national survey, we observed that in both the populations studied, homedwellers and patients living in an institution, $80 \%$ of persons stated that they had no problems of caries, loosened teeth and receding gums, or dental abscesses, whereas the literature demonstrates that this population has an objective and increasing need of care. ${ }^{18}$ They appear to be unaware of their state of oral health, and this may be a further obstacle to professional management.

As part of a field survey on institutionalized populations, we thought it useful to examine the objective and the perceived oral health of the residents.

The aim of this study was to compare the perceived oral health of elderly persons and the clinical reality. Understanding what may influence their perception can help us to improve their management.

\section{Materials and methods}

We carried out our study in two residential nursing homes for the elderly in southern France, where we collected administrative and medical data as well as data on the residents' oral health. We present here our findings on the objective and the perceived oral health of the residents of these institutions.

\section{Sample and study population}

The two institutions for the dependent elderly people (for its French acronym) in which we carried out our research were situated in southern France, one in a rural area $(n=53)$ and the other in an urban area $(\mathrm{n}=119)$, with a total of 172 residents. As part of our research protocol, an agreement was made with each institution and a consent form was given to each resident. One hundred fourteen residents subsequently agreed to take part in the survey $(n=43$ in the rural area, $n=71$ in the urban area). The characteristics of our sample are presented in Table 1.

\section{Objective oral health variables}

In order to assess the factors of objective oral health, our research protocol was based on intraoral clinical examination of the 114 residents, carried out by a dental surgeon.

Firstly, this examination defined four oral profiles:

- teeth/denture: teeth present on at least one of the two dental arches, with a partial or full dental prosthesis on at least one of the two arches,

- teeth/no denture: teeth present on at least one of the two arches, no prosthesis,

- no teeth/denture: no teeth on either of the two arches and a full prosthesis on at least one of the two arches,

- no teeth/no denture: no teeth on either arcade, no prosthesis.

To determine an oral health index, we used the French version of the Oral Health Assessment Tool (OHAT), validated by Chalmers et al in 2005. ${ }^{19}$ This tool provided an overall view of the state of the mouth and identified the unhealthy areas likely to lead to deterioration in oral health and in the patient's comfort. It also had the major advantage of not calling on the patient's capacity to understand and to express themselves, so persons with cognitive disorders could be evaluated. ${ }^{20,21}$

The OHAT is composed of eight items: lips, tongue, gum and tissues, saliva, natural teeth, dentures, oral cleanliness and 
Table I Characteristics of the sample of elderly nursing home residents $(n=|| 4)$

\begin{tabular}{|l|l|l|l|}
\hline & {$[$ min; max] } & Mean (SD) & Median [QI; Q3] \\
\hline $\begin{array}{l}\text { Men }(n=26) \\
\text { Age }\end{array}$ & & & \\
Length of stay in institution & {$[73.50 ; 93.4 I]$} & $83.65(5.48)$ & $84.11[80.42 ; 87.28]$ \\
& {$[0.06 ; 12.33]$} & $4.28(3.27)$ & $3.35[2.13 ; 5.08]$ \\
\hline Women $(n=88)$ & & & $89.19[82.78 ; 93.70]$ \\
Age & {$[62.62 ; 104.17]$} & $88.16(7.88)$ & $4.31[2.40 ; 7.25]$ \\
Length of stay in institution & {$[0.02 ; 12.70]$} & $4.53(2.74)$ & \\
\hline Total $(n=114)$ & & & $88.09[81.59 ; 93.11]$ \\
Age & {$[62.62 ; 104.17]$} & $87.13(7.62)$ & $4.05[2.28 ; 7.05]$ \\
Length of stay in institution & {$[0.02 ; 12.70]$} & $4.47(2.85)$ & \\
\hline
\end{tabular}

dental pain (Table 2). Each item is coded 0,1 or 2 . A score of 0 corresponds to absence of disorder, a score of 1 indicates a noticeable but not pathological change in the criterion assessed, and a score of 2 indicates pathological features. The total OHAT score ranges from 0 to 16 and can be classified into three categories:

- $[0 ; 3]$, healthy mouth, to be maintained by usual care.

- $[4 ; 8]$, changes observed and monitoring required, as there are areas of weakness.

- $[9 ; 16]$, unhealthy mouth: care needs to be planned and the specialized opinion of a dental surgeon should be proposed.

\section{Variables of perceived oral health}

We used the General Oral Health Assessment Index (GOHAI) to evaluate oral health-related quality of life. ${ }^{22}$ This questionnaire, developed by Atchison and Dolan, ${ }^{23}$ has been widely used to evaluate oral health in clinical or epidemiological studies. It was initially validated in the United States and has since been validated in several languages, ${ }^{24-28}$ notably in French. ${ }^{29}$ Subjects were asked if they had always, often, sometimes, seldom or never experienced any of the cited problems in the past month. Questions were worded sometimes positively, sometimes negatively, so that respondents needed to reflect on their answers. Responses were scored on a scale ranging from 1 to 5 .

The total score on the GOHAI ranges from 12 to 60 . The higher the score, the better the quality of oral health (Table 3 ). The score obtained was classified into three categories:

- $[12 ; 50]$ : low score, poor oral quality of health

- $[51 ; 56]$ : intermediate score, medium oral quality of health,

- [57; 60]: high score, good oral quality of health.
The 12 questions of the GOHAI can be grouped together in three fields:

- Functional (eating, speaking, swallowing), corresponding to items $1-4$, with a total score of 4 to 20 ,

- Psychosocial (concerns, relational discomfort, appearance), corresponding to items $6,7,9,10$ and 11, with a total score of 5 to 25 ,

- Pain or discomfort (drugs, sensitive gums, discomfort when chewing certain foods), corresponding to items 5,8 and 12 , with a total score of 3-15.

\section{Statistical analysis}

A detailed descriptive analysis was performed. Qualitative variables were presented as numbers and percentages (n, \%). Quantitative variables were expressed as means and SD as well as medians sorted at the 25th and 75th percentiles (interquartile interval).

The Fisher exact test was used to test the association between two categorical variables. The non-parametric Spearman's test was applied to evaluate a possible correlation between the number of years spent in the institution and GOHAI and OHAT scores, respectively. The Cochran-Armitage test was used to assess trends in the proportion of individuals with poor self-perceived oral health according to their objective OHAT category. The three GOHAI subscore distributions between levels of the oral profile variable were compared by the non-parametric Kruskal-Wallis test. Pairwise exact Wilcoxon rank sum tests were subsequently conducted to examine differences between the four profiles where significance was observed at the $10 \%$ level. Post-hoc pairwise Fisher exact tests were performed to test associations between OHAT in three categories and each pair of oral profiles. For all pairwise comparisons, the False Discovery 
Table 2 Oral Health Assessment Tool (OHAT) for dental screening

\begin{tabular}{|c|c|c|c|}
\hline Category & $0=$ healthy & $I=$ changes & $2=$ unhealthy \\
\hline Lips & Smooth, pink, moist & $\begin{array}{l}\text { Dry, chapped or red at } \\
\text { corners }\end{array}$ & $\begin{array}{l}\text { Swelling or lump, white/red/ulcerated patch; } \\
\text { bleeding/ulcerated at corners }\end{array}$ \\
\hline Tongue & $\begin{array}{l}\text { Normal, moist roughness, } \\
\text { pink }\end{array}$ & $\begin{array}{l}\text { Patchy, fissured, red, } \\
\text { coated }\end{array}$ & Patch that is red and/or white, ulcerated, swollen \\
\hline Gums and tissues & $\begin{array}{l}\text { Pink, moist, smooth, no } \\
\text { bleeding }\end{array}$ & $\begin{array}{l}\text { Dry, shiny, rough, red, } \\
\text { swollen, one ulcer/sore } \\
\text { spot under dentures }\end{array}$ & $\begin{array}{l}\text { Swollen, bleeding, ulcers, white/red patches, gen- } \\
\text { eralized redness under dentures }\end{array}$ \\
\hline Saliva & $\begin{array}{l}\text { Moist tissues, watery and } \\
\text { free flowing saliva }\end{array}$ & $\begin{array}{l}\text { Dry, sticky tissues, little } \\
\text { saliva present, resident } \\
\text { thinks they have a dry } \\
\text { mouth }\end{array}$ & $\begin{array}{l}\text { Tissues parched and red, very little/no saliva pre- } \\
\text { sent, saliva is thick, resident thinks they have a dry } \\
\text { mouth }\end{array}$ \\
\hline Natural teeth & $\begin{array}{l}\text { No decayed or broken } \\
\text { teeth/roots }\end{array}$ & $\begin{array}{l}\text { I-3 decayed or broken } \\
\text { teeth/roots or very worn } \\
\text { down teeth }\end{array}$ & $\begin{array}{l}4+\text { decayed or broken teeth/roots, or very worn } \\
\text { down teeth, or less than } 4 \text { teeth }\end{array}$ \\
\hline Dentures & $\begin{array}{l}\text { No broken areas or teeth, } \\
\text { dentures regularly worn, } \\
\text { and named }\end{array}$ & $\begin{array}{l}\text { I broken area/tooth or } \\
\text { dentures only worn for } \\
\text { I-2 hrs daily, or dentures } \\
\text { not named, } \\
\text { or loose }\end{array}$ & $\begin{array}{l}\text { More than I broken area/tooth, denture missing or } \\
\text { not worn, loose and needs denture adhesive, } \\
\text { or not named }\end{array}$ \\
\hline Oral cleanliness & $\begin{array}{l}\text { Clean and no food parti- } \\
\text { cles or tartar in mouth or } \\
\text { dentures }\end{array}$ & $\begin{array}{l}\text { Food particles/tartar/pla- } \\
\text { que in I-2 areas of the } \\
\text { mouth or on small area of } \\
\text { dentures or halitosis (bad } \\
\text { breath) }\end{array}$ & $\begin{array}{l}\text { Food particles/tartar/plaque in most areas of the } \\
\text { mouth or on most of dentures or severe halitosis } \\
\text { (bad breath) }\end{array}$ \\
\hline Dental pain & $\begin{array}{l}\text { No behavioral, verbal, or } \\
\text { physical signs of dental } \\
\text { pain }\end{array}$ & $\begin{array}{l}\text { Verbal and/or behavioral } \\
\text { signs of pain such as pull- } \\
\text { ing at face, chewing lips, } \\
\text { not eating, aggression }\end{array}$ & $\begin{array}{l}\text { Signs of physical pain (swelling of cheek or gum, } \\
\text { broken teeth, ulcers), as well as verbal and/or } \\
\text { behavioral signs (pulling at face, not eating, } \\
\text { aggression) }\end{array}$ \\
\hline & & & Total score: /16 \\
\hline
\end{tabular}

Rate (FDR) approach was used to correct for multiple testing.

Statistical analyses were performed using SAS 9.4 software (SAS Institute Inc., Cary, NC, USA) and R Software version 3.5.1 (R Foundation for Statistical Computing, Vienna, Austria). All statistical tests were two-sided except for the Cochran-Armitage test, and the significance level used was 0.05 .

\section{Ethics}

The investigation conformed to the provisions of the Declaration of Helsinki and the agreement of the Ethics Committee of Aix-Marseille University was obtained before starting. All the participants provided written informed consent.

\section{Results}

The data on oral health are based on the sample of 114 individuals. Evaluation of perceived oral health requires the patient's cooperation, and so the sample consisted of 94 individuals as 20 residents in the total population were unable to respond during the interview because of decreased ability to understand or to cooperate. Distribution of residents according to oral profiles and OHAT and GOHAI categories is shown in Table 4. 
Table $3 \mathrm{GOHAl}$ items and frequency distribution of the responses $(n=94)$

\begin{tabular}{|c|c|c|c|c|c|}
\hline In the past month... & Never & Seldom & Sometimes & Often & Always \\
\hline $\begin{array}{l}\text { I - How often did you limit the kinds or amounts of food you eat } \\
\text { because of problems with your teeth or denture? }\end{array}$ & $34(36.17)$ & $20(21.28)$ & $12(12.77)$ & $25(26.60)$ & $3(3.19)$ \\
\hline $\begin{array}{l}2 \text { - How often did you have trouble biting or chewing any kinds of } \\
\text { food, such as firm meat or apples? }\end{array}$ & $18(19.15)$ & $21(22.34)$ & $18(19.15)$ & $33(35.11)$ & $4(4.26)$ \\
\hline 3 - How often were you able to swallow comfortably? & $2(2.13)$ & $3(3.19)$ & $5(5.32)$ & $13(13.83)$ & $71(75.53)$ \\
\hline $\begin{array}{l}4 \text { - How often have your teeth or dentures prevented you from } \\
\text { speaking the way you wanted? }\end{array}$ & $61(64.89)$ & $19(20.21)$ & $9(9.57)$ & $4(4.26)$ & $\mathrm{I}(\mathrm{I} .06)$ \\
\hline $\begin{array}{l}5 \text { - How often were you able to eat anything without feeling } \\
\text { discomfort? }\end{array}$ & 0 & $23(24.47)$ & $8(8.51)$ & $30(31.91)$ & $33(35.11)$ \\
\hline $\begin{array}{l}6 \text { - How often did you limit contacts with people because of the } \\
\text { condition of your teeth or denture? }\end{array}$ & $72(76.60)$ & $12(12.27)$ & $8(8.51)$ & $2(2.13)$ & 0 \\
\hline $\begin{array}{l}7 \text { - How often were you pleased or happy with the looks of your } \\
\text { teeth, gums or dentures? }\end{array}$ & $7(7.45)$ & $15(15.96)$ & $5(5.32)$ & $17(18.09)$ & $50(53.19)$ \\
\hline $\begin{array}{l}8 \text { - How often did you use medication to relieve pain or discomfort } \\
\text { from around your mouth? }\end{array}$ & $27(28.72)$ & $18(19.15)$ & $30(31.91)$ & $19(20.21)$ & 0 \\
\hline $\begin{array}{l}9 \text { - How often were you worried or concerned about the problems } \\
\text { with your teeth, gums or dentures? }\end{array}$ & $18(19.15)$ & 31 (32.98) & $21(22.34)$ & $24(25.53)$ & 0 \\
\hline $\begin{array}{l}10 \text { - How often did you feel nervous or self-conscious because of } \\
\text { problems with your teeth, gums or dentures? }\end{array}$ & $33(35.11)$ & $26(27.66)$ & $20(21.28)$ & $14(14.89)$ & I (1.06) \\
\hline $\begin{array}{l}\text { II - How often did you feel uncomfortable eating in front of people } \\
\text { because of problems with your teeth or dentures? }\end{array}$ & $50(53.19)$ & $29(30.85)$ & $13(13.83)$ & I (I.06) & I (1.06) \\
\hline $\begin{array}{l}12 \text { - How often were your teeth or gums sensitive to hot, cold or } \\
\text { sweets? }\end{array}$ & $20(21.28)$ & 14 (14.89) & $4 \mid(43.62)$ & $18(19.15)$ & I (1.06) \\
\hline
\end{tabular}

Abbreviation: GOHAI, General Oral Health Assessment Index.

\section{Objective oral health}

\section{Oral profiles}

The residents' oral profile was determined in the first intraoral clinical examination. Nearly $43 \%$ of residents had a denture that replaced all or some of the missing teeth and $39.47 \%$ of

Table 4 Distribution of residents according to objective and perceived state of oral health

\begin{tabular}{|l|l|l|}
\hline & $\mathbf{n}$ & $\%$ \\
\hline Oral profile (n=I14) & & \\
Teeth/denture & 21 & 18.42 \\
Teeth/no denture & 48 & 42.11 \\
No teeth/denture & 28 & 24.56 \\
No teeth/no denture & 17 & 14.91 \\
\hline OHAT (n=II4) & & \\
Healthy & 21 & 18.42 \\
Changes & 61 & 53.51 \\
Unhealthy & 32 & 28.07 \\
\hline GOHAI (n=94) & & \\
Poor QoL & 50 & 53.19 \\
Medium QoL & 36 & 38.30 \\
Good QoL & 8 & 8.51 \\
\hline
\end{tabular}

Abbreviations: GOHAI, General Oral Health Assessment Index; OHAT, Oral Health Assessment Tool. residents had no teeth on either of the two arches (total edentation).

\section{OHAT}

Examination based on the OHAT yielded the overall OHAT score and the score for each item for all residents (Table 5). In our sample, the total score ranged between 1 and 12, distributed between the three categories as follows: $18.42 \%$ of residents had a healthy mouth, $53.51 \%$ showed changes requiring monitoring and $28.07 \%$ had an unhealthy mouth giving cause for concern.

\section{Perceived oral health}

Evaluation of perceived oral health using the GOHAI questionnaire showed that over half of the residents who responded $(53.19 \%)$ stated that they had a poor oral quality of life while $8.51 \%$ stated that they had a good oral quality of life. Over $38 \%$ stated that they had a medium oral quality of life. Mean GOHAI score was 46.67 , indicating the poor perceived oral quality of life.

Data on the three GOHAI fields for the 94 residents who participated in the interview are presented in Table 6.

OHAT and perceived oral health according to the length of stay in the institution 
Table 5 Overall and itemized OHAT score $(n=\mid 14)$

\begin{tabular}{|l|l|l|}
\hline Variable & {$[$ min; max $]$} & Mean (SD) \\
\hline Lips & {$[0 ; 2]$} & $0.57(0.68)$ \\
Tongue & {$[0 ; 2]$} & $0.71(0.56)$ \\
Gums and tissues & {$[0 ; 2]$} & $0.75(0.74)$ \\
Saliva & {$[0 ; 2]$} & $0.74(0.57)$ \\
Natural teeth & {$[0 ; 2]$} & $1.59(0.68)$ \\
Dentures & {$[0 ; 2]$} & $0.46(0.82)$ \\
Oral cleanliness & {$[0 ; 2]$} & $1.07(0.58)$ \\
Dental pain & {$[0 ; 2]$} & $0.45(0.61)$ \\
OHAT score & {$[1 ; 12]$} & $6.33(3.04)$ \\
\hline
\end{tabular}

Abbreviation: OHAT, Oral Health Assessment Tool.

The overall OHAT score and length of stay in the institution showed a significant positive correlation $(\rho=0.257$; $P=0.006$ ). Although the correlation is weak, the longer the stay in the institution, the higher the OHAT score, and so the state of oral health is a cause of concern. The correlation between the overall GOHAI score and length of stay in the institution did not significantly differ from $0(P=0.406)$.

OHAT and perceived oral health according to oral profile (Figure 1)

Distribution of the residents according to the three OHAT categories for each oral profile is shown at the top of Figure 1. The Fisher exact test revealed a significant association between OHAT categories and oral profile $(P=0.004)$. Post-hoc pairwise exact Fisher tests showed a significant difference between the teeth/denture and no teeth/no denture profiles (FDR-corrected $P=0.003$ ).

Analysis of the three GOHAI categories in relation to oral profile (at the bottom of Figure 1) shows that residents who reported good oral quality of life were those who were dentate: the edentate residents, with or without dentures, never reported good oral quality of life.

A large proportion of individuals reported a medium oral quality of life $(25 \%-43.3 \%)$ whatever their oral profile. The proportion of individuals who reported poor oral quality of life was practically identical for both dentate profiles (45\% with dentures, 43.65\% without dentures).
This proportion was very high for the totally edentate profile, $66.67 \%$ for those with dentures and $75 \%$ for those without dentures. However, the Fisher exact test showed no significant association between OHAT categories and oral profile $(P=0.221)$.

Looking more closely at the three GOHAI fields taken separately and according to the oral profile (Figure 2), we see that the smallest value of the median is that of the no teeth/no denture profile for each of the three domains. The Kruskal-Wallis test showed that at least one of the four profiles differed from at least one of the others regarding the GOHAI subscore related to the functional field $(P<0.001)$. All pairwise comparisons showed significant differences between the profiles in terms of functional field subscore except for "teeth/no denture" vs "teeth/denture" and "no teeth/no denture" vs "no teeth/denture". The $P$-value for the GOHAI subscore associated with the psychosocial field (rdiscomfort/pain) was 0.069 (0.889). Concerning the psychological field subscore (where global significance was observed at $10 \%$ level), only the "no teeth/no denture" vs "teeth/denture" comparison was significant (FDR-corrected $P=0.044$ ).

Objective and perceived state of oral health (Figure 3)

Secondly, we examined the oral state of health reported by the residents according to the three GOHAI categories which we associated with the three OHAT categories established during the clinical examination. We observed a significant association $(P<0.001$, Fisher exact test) between the OHAT variable and the GOHAI variable. The Cochran-Armitage test showed that the percentage of persons reporting poor oral health decreased as objective oral health improved (one-tailed $P<0.001$ ).

\section{Discussion}

Maintaining optimal oral health is a challenge for those caring for elderly institutionalized persons. If not maintained, oral health can rapidly deteriorate and so compromise general health and quality of life. ${ }^{30}$

Table 6 Global and field GOHAI scores $(n=94)$

\begin{tabular}{|l|l|l|l|l|}
\hline Variable & {$\left[\mathbf{m i n}_{\text {th }} ; \mathbf{m a x}_{\mathbf{t h}}\right]$} & {$\left[\mathbf{m i n}_{\mathbf{o b s}} ; \mathbf{m a x}_{\mathbf{o b s}}\right]$} & Mean (SD) & Median [QI; Q3] \\
\hline Functional field & {$[4 ; 20]$} & {$[9 ; 20]$} & $15.79(3.35)$ & $16.00[13.00 ; 19.00]$ \\
Psychosocial field & {$[5 ; 25]$} & {$[9 ; 25]$} & $20.18(4.15)$ & $21.00[17.00 ; 24.00]$ \\
Pain or discomfort field & {$[3 ; 15]$} & {$[6 ; 15]$} & $10.70(2.70)$ & $11.00[8.00 ; 13.00]$ \\
GOHAl score & {$[12 ; 60]$} & {$[29 ; 59]$} & $46.67(8.90)$ & $49.00[38.00 ; 54.00]$ \\
\hline
\end{tabular}

Notes: $\left[\min _{\mathrm{th}} ; \max _{\mathrm{th}}\right]$ : theoretical. [ $\left.\min _{\mathrm{obs}} ; \max _{\mathrm{obs}}\right]$ : observed.

Abbreviation: GOHAl, General Oral Health Assessment Index. 


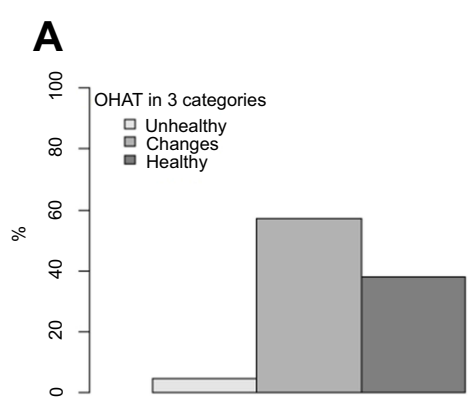

1. Teeth/denture

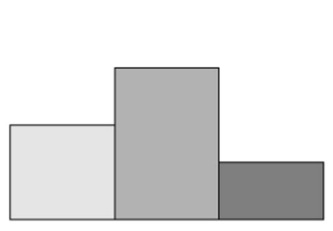

2. Teeth/no denture

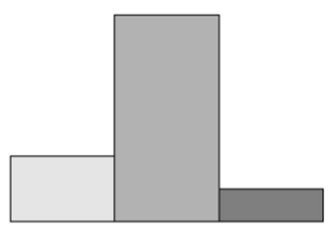

3. No teeth/denture

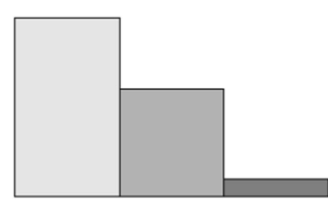

4.No teeth/no denture Oral profile

\section{B}

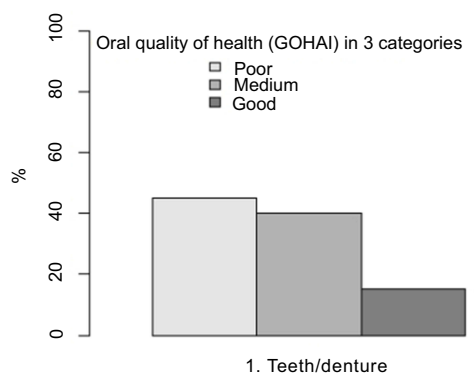

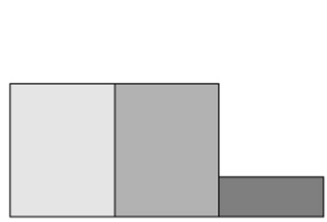

2. Teeth/no denture

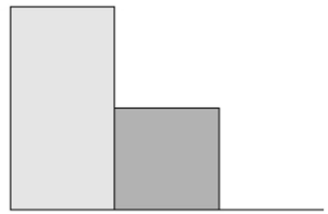

3. No teeth/denture

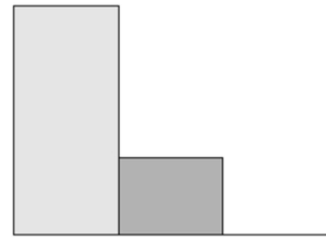

4. No teeth/no denture

Oral profile

Figure I (A) Objective oral health (OHAT) according to oral profile $(n=|| 4)$. (B) Perceived oral health (GOHAI) according to oral profile ( $n=94)$.

Abbreviations: OHAl, General Oral Health Assessment Index; OHAT, Oral Health Assessment Tool; PFDR, p-value associated with exact Wilcoxon rank sum test after FDR-correction; PKW, p-value associated with Kruskal-Wallis test.

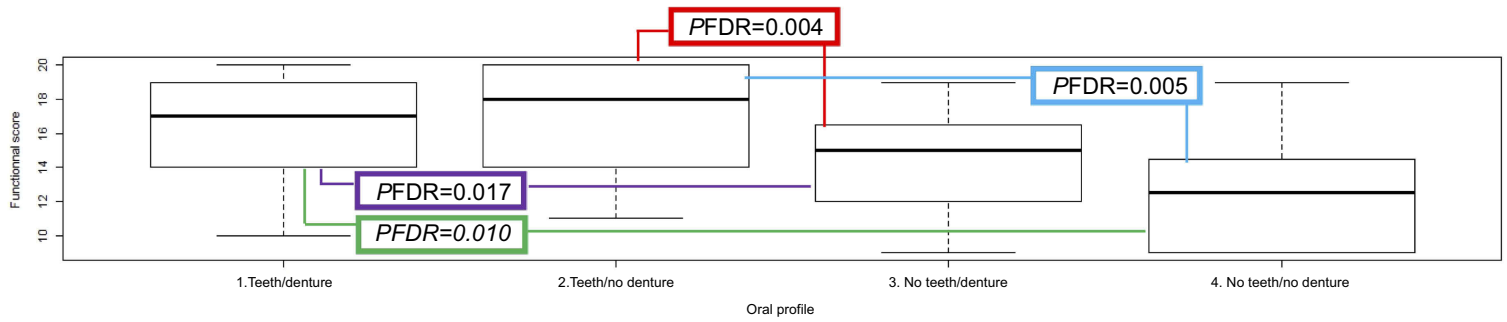

$P K W<0.001$

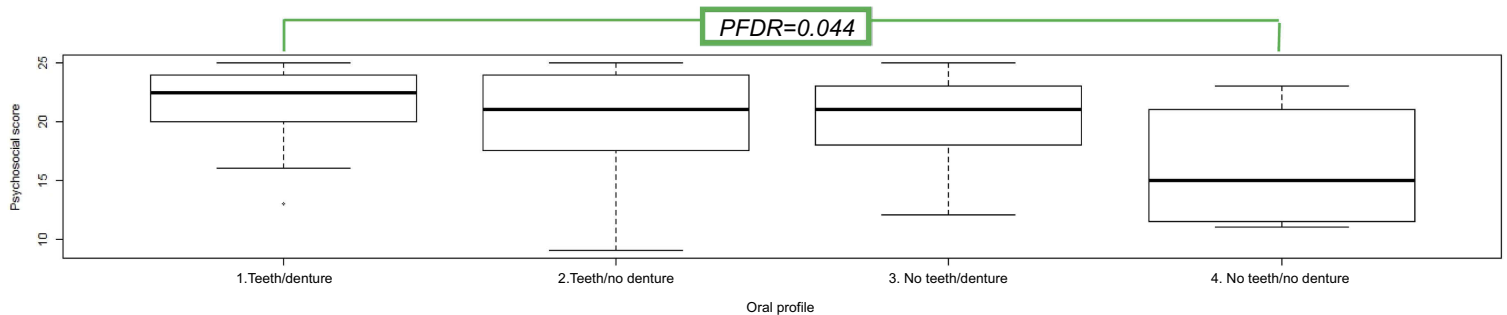

$P K W=0.069$

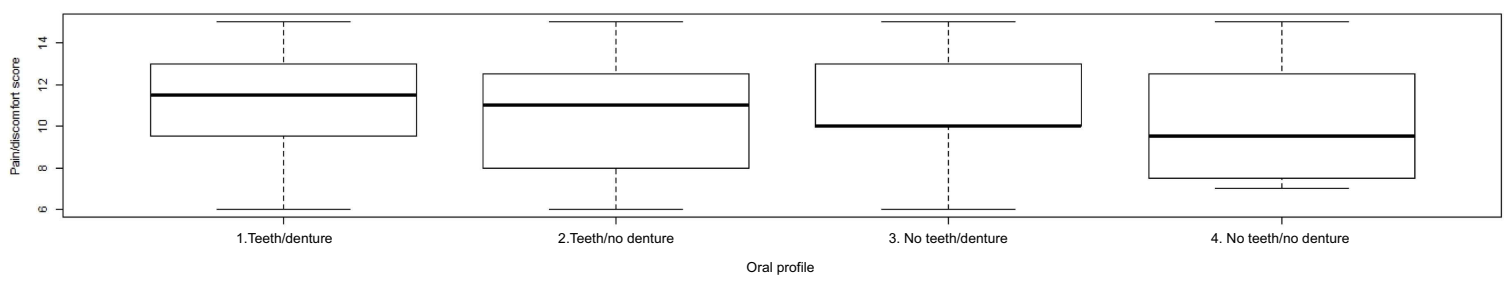

$P K W=0.889$

Figure 2 Boxplot representations of the three GOHAl subscores by oral profile.

Note: Only significant pairwise comparisons after FDR-correction are added on the graphs.

Abbreviations: FDR, false discovery rate; GOHAl, General Oral Health Assessment Index; OHAT, Oral Health Assessment Tool. 

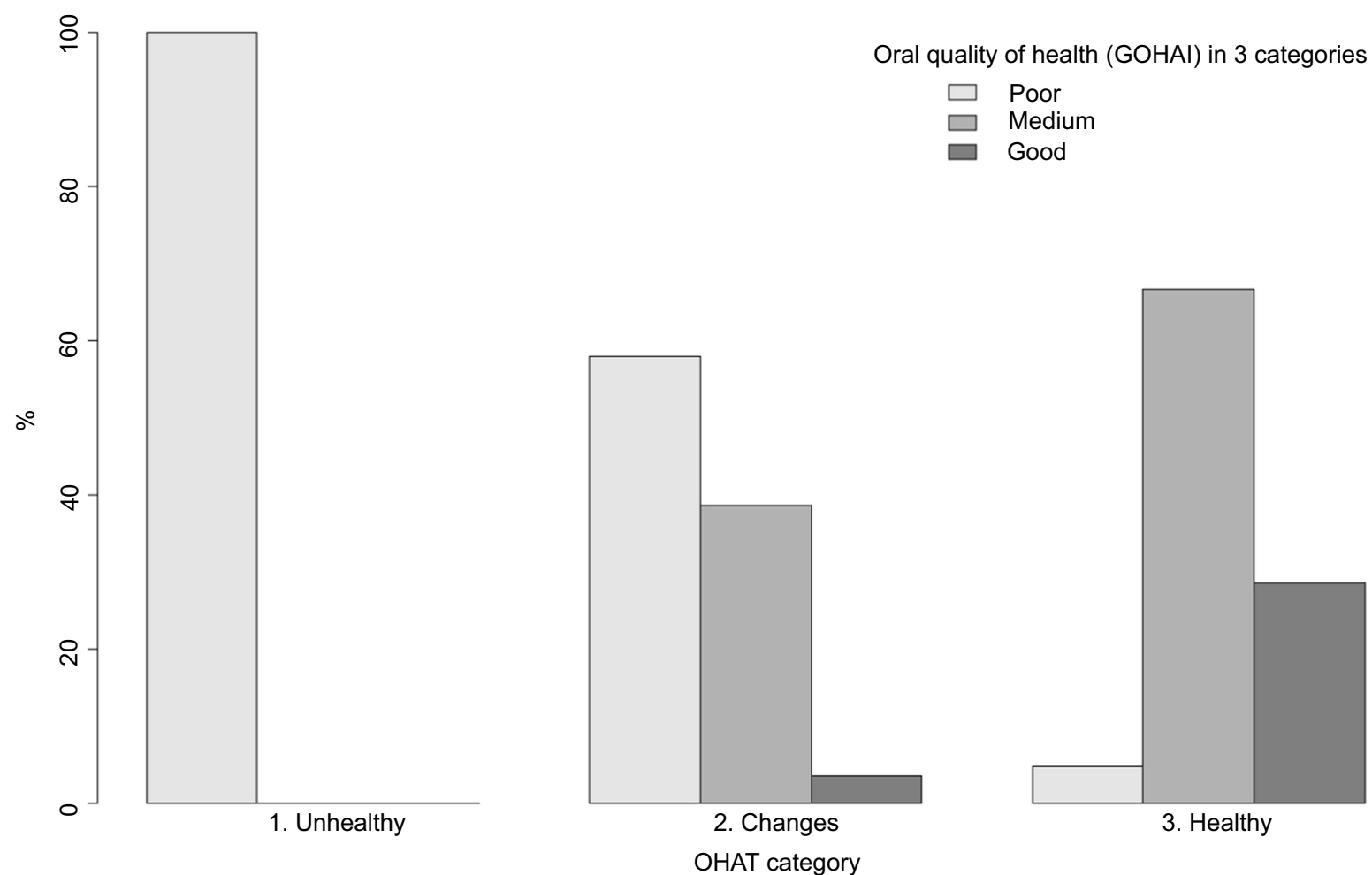

Figure 3 Perceived oral health (OHAT) according to oral profile $(n=94)$.

Abbreviations: GOHAI, General Oral Health Assessment Index; OHAT, Oral Health Assessment Tool.

It is of primary importance that care teams should be able to intervene early and simply. Ideally, intervention would be based on the health status reported by the patient, thus avoiding clinical examination and saving time and money. However, our clinical study showed a discrepancy between perceived oral health and the clinical reality: although a significant association can be demonstrated between the OHAT and the GOHAI, there are considerable variations. This situation has been described in the literature, and many studies have found no link between clinical and perceived health. Elderly patients may state that they are satisfied with their oral health, whereas clinical examination shows poor clinical status or the contrary. This is because the disease is measured by an objective indicator, whereas a subjective indicator reflects perceived health and is associated with human experience. ${ }^{31,32}$ It therefore seems important to analyze the determinants of perception of such health, in order to establish what may be the clinical and subjective factors that influence elderly persons' perception of their oral health.

When in our study we look at the oral profile, it appears that perceived oral health is greatly influenced by the number of teeth and total edentation and that the findings vary depending on the situations. The same debate is found in the literature, where total edentation is presented as a factor that is positively associated with the perception of health due to the absence of caries, pain or discomfort. ${ }^{32,33}$ Patients also become accustomed to their lack of teeth, with or without dentures, as they consider that it is part of the aging process. Conversely, another study stated that edentation was associated with a negative perception if the patient feels the need for care and/or has trouble in chewing or a disturbance of taste. ${ }^{34}$ Andrade et $\mathrm{al}^{35}$ were in agreement while stressing that edentate persons have a more negative perception of health than dentate persons, although this relation is not truly predictive of perception of oral health. Lastly, loss of a tooth affects perception of oral health, but it is not a very powerful marker as it can influence perception negatively or positively depending on the conditions in which the tooth was lost: ${ }^{36}$ cessation of acute pain, maintenance of chewing ability, anterior or posterior location of the tooth, tooth replaced or not. It is also necessary to take into account the need for prosthetic rehabilitation which may sometimes be underestimated by the patients. Several studies have shown that the perceived 
need for a prosthesis is associated with poor perceived oral health. Silva et $\mathrm{al}^{37}$ observed that the lowest GOHAI scores were those of patients who expressed the need for prostheses, while Schutzhold et $\mathrm{al}^{38}$ found a correlation between the number of unreplaced missing teeth and negative perception of oral health. In the study of Esmeriz et $\mathrm{al}^{39}$ the wearing of a prosthesis was associated with a positive perception. Several authors ${ }^{38,40,41}$ also explain that a prosthesis restores the patients' function and esthetics, and so improves selfimage. Wearing dentures may be considered as the elderly person's wish to restore their oral health, regain a good self-image and self-esteem. It may also be suggested that the need for a prosthesis is related to the patient's impression that they need care, and so by extension to a negative perception of health.

We may also consider the quality of prostheses: use of removable prostheses can be a negative factor of oral health, ${ }^{37}$ particularly if they are not functional and the patient cannot chew comfortably. Conversely, a removable prosthesis may be associated with better chewing and so with better perceived oral health. ${ }^{42}$ In their study published in 2011, Silva et $\mathrm{al}^{43}$ found a positive association between perceived oral health and full dentures on both arches, which appeared to improve the oral health of the elderly persons. Lastly, regarding the absence of rehabilitation, we point out the study of Ugarte et $\mathrm{al}^{44}$ in Bolivia, where many patients stated that they could chew well without prostheses. In this case, the culture and health perception of the patients concerned or their limited access to dental care lead them to accept the deterioration of their oral condition.

It is thus understandable that at this stage, the diversity of perceptions, clinical situations, general health, type of food or the patient's dental history as well as many other factors have an impact on the patient's self-perceived oral health, which may be very different from that diagnosed on clinical examination.

In our work, we share this analysis when we attempt to cross-analyze the GOHAI and OHAT data: while we demonstrated that the percentage of individuals reporting poor oral health decreases when objective oral health improves, nevertheless we observe that the patient's perception of oral health may vary greatly even though clinical examination has shown a healthy mouth or one with changes requiring observation.

The literature shows that the GOHAI is an indicator of patients' oral quality of life, but that it does not reflect the clinical situation. ${ }^{35,39,45,46}$ In their study, Andrade et al ${ }^{35}$ observed a significant link between positive perception of oral health and a high GOHAI score in three of its dimensions (pain, psychosocial, functional), as well as a relation between a negative perception of health and a low score in the psychosocial field. Another study has also shown a relationship between negative perception of oral health and a low score in the psychosocial and functional fields. ${ }^{46}$ The last two studies stress the usefulness of preferentially taking into consideration the overall score, the three categories of the GOHAI, in order to identify more specifically the patients' subjective needs.

Finally, we will highlight the notion of resilience developed by some authors. ${ }^{47,48}$ Resiliency can play an important role in explaining the difference between objective and perceived oral health. Resilience is one of the positive individual traits that can ultimately contribute to active and healthy aging. The concept of resilience refers to a dynamic process involving social or personal psychic factors that are important for healthy development, even in a situation of weakness. Older people who are more resilient can adapt more easily to losses related to oral health. Therefore, the self-perceived quality of oral life appears better.

\section{Conclusion}

The aim of this work was to understand what can influence elderly persons' perception of oral health, in order to help to improve their management. Self-perception of oral health in the elderly appears to be influenced by a multitude of intrinsic and extrinsic factors such as the direct and indirect environment, the social and cultural milieu, education, type of residential arrangement and also oral health status. Several authors have addressed this subject and shown its intrinsic difficulties and have also opened up new perspectives and axes of reflection such as the notion of resilience. A high potential of resilience could, as it were, enable patients to more easily accept dentures or the loss of a tooth and so improve selfesteem and quality of life. The ability to adapt is very certainly a factor that influences perceived oral health, and one on which it is possible to act by information, education and the introduction of simple measures of assistance in order to help seniors to age well.

\section{Disclosure}

The authors report no conflicts of interest in this work. 


\section{References}

1. World Health Organization. World Oral Health Report. Geneva, Switzerland: WHO; 2003.

2. Bontout $\mathrm{O}$, Colin C, Kerjosse R. Personnes âgées dépendantes et aidants potentiels: une projection à l'horizon 2040 [Disabled older people and their carers: a projection to the year 2040]. Etudes Et Résultats. 2002;160:1-10. French.

3. Blanpain N, Chardon O. Projections de population à l'horizon 2060 [Projections of population by 2060]. Paris: Insee Première; 2010. French.

4. Duée M, Rebillard C. La dépendance des personnes âgées: une projection en 2040. Santé et protection sociale [Dependency of the elderly: a projection in 2040. Health and social protection]. Données Sociales. 2006:7;613-619. French.

5. Mack F, Mojon P, Budtz-Jorgensen E, et al. Caries and periodontal disease of the elderly in Pomerania, Germany: results of the study of health in Pomerania. Gerodontology. 2004;21:27-36. doi:10.1046/ j.1741-2358.2003.00001.x

6. Folliguet M, Veille-Finet A, Tavernier JC, et al. Dental and nutritional status of long-term care institutionalised old adults. Age Nutr. 2004;15:84-89.

7. Chiappelli F, Bauer J, Spackman S, et al. Dental needs of the elderly in the 21 st century. Gen Dent. 2002;50:358-363.

8. Frenkel H. Alzheimer's disease and oral care. Dent Update. 2004;31:273-278. doi:10.12968/denu.2004.31.5.273

9. Chalmers JM, Carter KD, Spencer AJ. Oral diseases and conditions in community-living older adults with and without dementia. Spec Care Dentist. 2003;23:7-17. doi:10.1111/j.1754-4505.2003.tb00283.x

10. Pouyssegur V, Precheur I, Sabot JG. Maladies bucco-dentaires: cofacteurs de morbidité des personnes âgées [Oral diseases: cofactors of morbidity of the elderly]. Rev Geriatr. 2016;41(1):17-31. French.

11. Radoï L, Veille Finet A, Dupuis V, Folliguet M. Impact de l'état bucco-dentaire sur la santé générale: actualisation des connaissances [Impact of oral status on general health: actualization of knowledge]. Rev Geriatr. 2016;41(1):5-16. French

12. Ruquet M, Maille G, Tavitian P, Tardivo D, Hüe O, Bonfil JJ. Alveolar bone loss and ageing: possible association with coronary heart diseases and/or severe vascular diseases. Gerodontology. 2016;33(3):356-362. doi:10.1111/ger.12168

13. Shah SM, Carey IM, Harris T, Dewilde S, Cook DG. Quality of chronic disease care for older people in care homes and the community in a primary care pay for performance system: retrospective study. Bmj. 2011;342:912. doi:10.1136/bmj.d912

14. Fahey T, Montgomery AA, Barnes J, Protheroe J. Quality of care for elderly residents in nursing homes and elderly people living at home: controlled observational study. BMJ. 2003;326(7389):580. doi:10.1136/bmj.326.7402.1329-b

15. Thiébaut S, Lupi-Pégurier L, Paraponaris A, Ventelou A. Comparaison du recours à un chirurgien-dentiste entre les personnes âgées institutionnalisées et celles vivant à domicile, France 2008-2009. Bull Epidemiol Hebd. 2013;7:60-64. French.

16. Naito M, Kato T, Fujii W, et al. Effects of dental treatment on the quality of life and activities of daily living in institutionalized elderly in Japan. Arch Gerontol Geriatr. 2010;50:65-68. doi:10.1016/j. archger.2009.01.013

17. Donnelly LR, Clarke LH, Phinney A, MacEntee MI. The impact of oral health on body image and social interactions among elders in long-term care. Gerodontology. 2016;33(4):480-489. doi:10.1111/ger.2016.33. issue-4

18. Maille G, Saliba-Serre B, Ferrandez AM, Ruquet M. Use of care and the oral health status of people aged 60 years and older in France: results from the national health and disability survey. Clin Interv Aging. 2017;12:1159-1166. doi:10.2147/CIA.S135542
19. Chalmers JM, King PL, Spencer AJ. The oral health assessment tool - validity and reliability. Aust Dent J. 2005;50:191-199. doi:10.1111/j.1834-7819.2005.tb00360.x

20. Klotz AL, Hassel AJ, SchröDer J, et al. Oral health-related quality of life and prosthetic status of nursing home residents with or without dementia. Clin Interv Aging. 2017;12:659-665. doi:10.2147/CIA. S125128

21. Klotz AL, Zajac M, Ehret J, Hassel AJ, Rammelsberg P, Zenthöfer A. Development of a German version of the Oral Health Assessment Tool. Aging Clin Exp Res. Epub 2019 Mar 7.

22. Allen PF. Assessment of oral health related quality of life. Health Qual Life Outcomes. 2003;1:40. doi:10.1186/1477-7525-1-40

23. Atchison KA, Dolan TA. Development of the Geriatric Oral Health Assessment Index. J Dent Educ. 1990;54:680-687.

24. Wong MC, Liu JK, Lo EC. Translation and validation of the Chinese version of GOHAI. J Public Health Dent. 2002;62(2):78-83. doi:10.1111/j.1752-7325.2002.tb03426.x

25. Hägglin C, Berggren U, Lundgren J. A Swedish version of the GOHAI index. Psychometric properties and validation. Swed Dent J. 2005;29(3):113-124.

26. Naito M, Suzukamo Y, Nakayama T, Hamajima N, Fukuhara S. Linguistic adaptation and validation of the General Oral Health Assessment Index (GOHAI) in an elderly Japanese population. J Public Health Dent. 2006;66(4):273-275. doi:10.1111/j.17527325.2006.tb04081.x

27. Rezaei M, Rashedi V, Khedmati Morasae E. A Persian version of geriatric oral health assessment index. Gerodontology. 2014;33 (3):335-341. doi:10.1111/ger.12161

28. Niesten D, Witter D, Bronkhorst E, Creugers N. Validation of a Dutch version of the Geriatric Oral Health Assessment Index (GOHAI-NL) in care-dependent and care-independent older people. BMC Geriatr. 2016;16(1):53. doi:10.1186/s12877-016$0227-0$

29. Tubert-Jeannin S, Riordan PJ, Morel-Papernot A, Porcheray S, SabyCollet S. Validation of an oral health quality of life index (GOHAI) in France. Community Dent Oral Epidemiol. 2003;31:275-284. doi:10.1034/j.1600-0528.2003.t01-1-00006.x

30. Bertrand MF, Macqueron N, Balard P, Lupi-Pégurier L. Hiérarchiser les facteurs de risque de dégradation de la santé orale des personnes âgées dépendantes en EHPAD [Prioritize the risk factors for the deterioration of the oral health of elderly people who are dependent in EHPAD]. Rev Geriatr. 2015;40:261-270. French.

31. Martins AM, Barreto SM, Pordeus IA. Objective and subjective factors related to self-rated oral health among the elderly. Cad Saude Publica. 2009;25(2):421-435. Portuguese. doi:10.1590/ S0102-311X2009000200021

32. Martins AM, Barreto SM, Silveira MF, Santa-Rosa TT, Pereira RD. Self-perceived oral health among Brazilian elderly individuals. Rev Saude Publica. 2010;44(5):912-922. English, Portuguese

33. Northridge ME, Chakraborty B, Kunzel C, Metcalf S, Marshall S, Lamster IB. What contributes to self-rated oral health among community-dwelling older adults? Findings from the ElderSmile program. J Public Health Dent. 2012;72(3):235-245. doi:10.1111/ j.1752-7325.2012.00313.x

34. Ekanayke L, Perera I. Factors associated with perceived oral health status in older individuals. Int Dent J. 2005;55(1):31-37.

35. Andrade FB, Lebrão ML, Santos JL, Duarte YA, Teixeira DS. Factors related to poor self-perceived oral health among community-dwelling elderly individuals in Sao Paulo, Brazil. Cad Saude Publica. 2012;28 (10):1965-1975.

36. Locker D, Clarke M, Payne B. Self-perceived oral health status, psychological well-being, and life satisfaction in an older adult population. J Dent Res. 2000;79(4):970-975. doi:10.1177/ 00220345000790041301 
37. Silva DD, de Sousa Mda L, Wada RS. Self-perception and oral health conditions in an elderly population. Cad Saude Publica. 2005;21 (4):1251-1259. Portuguese. doi:10.1590/S0102-311X20050004000 28

38. Schutzhold S, Holtfreter B, Schiffner U, Hoffmann T, Kocher T, Micheelis W. Clinical factors and self-perceived oral health. Eur J Oral Sci. 2014;122(2):134-141. doi:10.1111/eos.12117

39. Esmeriz CE, Meneghim MC, Ambrosano GM. Self-perception of oral health in non-institutionalised elderly of Piracicaba city, Brazil. Gerodontology. 2012;29(2):281-289. doi:10.1111/j.17412358.2011.00464.x

40. Vilela EA, Martins AM, Barreto SM, Vargas AM, Ferreira RC. Association between self-rated oral appearance and the need for dental prostheses among elderly Brazilians. Braz Oral Res. 2013;27 (3):203-210. doi:10.1590/S1806-83242013005000010

41. Nunes CI, Abegg C. Factors associated with oral health perception in older Brazilians. Gerodontology. 2008;25(1):42-48. doi:10.1111/ j.1741-2358.2007.00163.x

42. Mariño R, Albala C, Sanchez H, Cea X, Fuentes A. Self-assessed oral-health status and quality of life of older Chilean. Arch Gerontol Geriatr. 2013;56(3):513-517. doi:10.1016/j.archger.2012.12.004

43. Silva DD, Held RB, Torres SV, Sousa Mda L, Neri AL, Antunes JL. Self-perceived oral health and associated factors among the elderly in Campinas, Southeastern Brazil, 2008-2009. Rev Saude Publica. 2011;45(6):1145-1153. doi:10.1590/S0034-89102011000600017
44. Ugarte J, Abe Y, Fukuda H, et al. Self-perceived oral health status and influencing factors of the elderly residents of a peri-urban area of La Paz, Bolivia. Int Dent J. 2007;57(1):19-26. doi:10.1111/j.1875595X.2007.tb00114.x

45. de Souza EH, Barbosa MB, de Oliveira PA, Espíndola J, Gonçalvez KJ. Impact of oral health in the daily life of institutionalized and non institutionalized elder in the city of Recife (PE, Brazil). Cien Saude Colet. 2010;15(6):2955-2964. Portuguese

46. Mesas AE, de Andrade SM, Cabrera MA. Factors associated with negative self-perception of oral health among elderly people in a Brazilian community. Gerodontology. 2008;25:49-56. doi:10.1111/j.1741-2358.2007.00196.x

47. Martins AB, Dos Santos CM, Hilgert JB, de Marchi RJ, Hugo FN, Pereira Padilha DM. Resilience and self-perceived oral health: a hierarchical approach. J Am Geriatr Soc. 2011;59(4):725-731. doi:10.1111/j.1532-5415.2011.03350.x

48. Teixeira MF, Martins AB, Celeste RK, Hugo FN, Hilgert JB. Association between resilience and quality of life related to oral health in the elderly. Rev Bras Epidemiol. 2015;18(1):220-233. doi:10.1590/1980-5497201500010017
Clinical Interventions in Aging

\section{Publish your work in this journal}

Clinical Interventions in Aging is an international, peer-reviewed journal focusing on evidence-based reports on the value or lack thereof of treatments intended to prevent or delay the onset of maladaptive correlates of aging in human beings. This journal is indexed on PubMed Central, MedLine, CAS, Scopus and the Elsevier
Dovepress

Bibliographic databases. The manuscript management system is completely online and includes a very quick and fair peer-review system, which is all easy to use. Visit http://www.dovepress.com/ testimonials.php to read real quotes from published authors. 